\title{
Abel Soler Molina, El corsari Jaume de Vilaragut i la donzella Carmesina. El cavaller que inspirà el "Tirant lo Blanc", València, Edicions Alfons el Magnànim («Estudis universitaris», núm. I33), 20I4. 2 vols. 98I pp. ISBN: 978-84-7822-639-9
}

El medievalista valencià Abel Soler Molina (Albaida, 1972) ha publicat un assaig biogràfic i interpretatiu sobre la plausible influència que les gestes del noble corsari Jaume de Vilaragut al Mediterrani als anys centrals del segle xv i les seves relacions amb la seva criada Carmesina pogueren exercir sobre Joanot Martorell (c. I4IO-I465) a l'hora d'elaborar el Tirant lo Blanch (I460-I464), publicat el I49O. Es tracta d'un estudi històric, basat en l'exhumació de molts documents de l'èpo$\mathrm{ca}$, de gran rellevància per a la història de la cultura de la València del segle xv i fins i tot de tota la Corona d'Aragó, incloent-hi els estats d'Itàlia que hi estaven llavors vinculats.

L'estudi arriba pràcticament al miler de pàgines, dividides en dos volums, però avancem-ho ja de passada, no hi sobra ni falta cap línia. El títol, que posa un èmfasi especial en la "donzella Carmesina», i el subtítol, que destaca el "cavaller que inspirà el Tirant» — tot un atreviment o una provocació, segons com es miri, per part de Soler-, condensen de forma molt precisa l'argument. Perquè, en definitiva, ens trobem davant d'una densa i documentadíssima biografia de Jaume de Vilaragut i Vilanova (c. I403 - c. I464) que ens detalla la quàdruple faceta del personatge: (a) com a corsari en la Corona d'Aragó; (b) com a baró de la important família nobiliària dels Vilaragut; (c) com un veritable «tirà» amb els vassalls de la «baronia blanca» (Albaida), i $(d)$, com un dels principals informadors de Joanot Martorell sobre el setge de Rodes, el Gran Caramany i el soldà de Babilònia. La principal novetat que aporta Soler és la d'unir aquests quatre aspectes, dels quals ja es comptava amb un cert coneixement previ, i la de fornir nova informació de gran interès sobre la presència d'una presumpta estimada del corsari anomenada Carmesina i sobre la relació del cavaller amb l'entorn familiar i social de Martorell. Una visió que li permet concloure de forma molt convincent que Jaume de Vilaragut - i no pas altres opcions alternatives que la crítica ha proposat al llarg dels anys - és el personatge real del qual parteix l'autor del Tirant per construir l'heroi de la seua ficció.

D'acord amb això, l'estudi, stricto sensu, es divideix en: (a) introducció i declaració d'intencions; (b) primera part (biogràfica, documental), i $(c)$ segona part (interpretativa).

L'historiador obre el primer volum — d'unes 400 pàgines — amb una «Introducció» (I3-26) que parteix dels estudis previs de dos grans historiadors de la cultura, Constantin Marinescu i Martí de Riquer, sobre la rellevància històrica de la figura 
de Jaume de Vilaragut, «amic» de Joanot Martorell. El mateix Riquer comenta en els seus treballs sobre el tema que, en llegir els detalls que coneixia sobre el corsari valencià —molt pocs llavors, en comparació amb els exhumats per Soler-, «el lector cree que está leyendo una síntesis de algunos episodios de la novela». Aquesta observació justificava, segons Soler, la necessitat d'aprofundir en el coneixement del personatge en qüestió amb la finalitat de tenir més elements per a ser capaços de poder discernir amb més precisió si existeix un «diàleg» entre «novel.la» i biografia. Soler aborda amb total solvència aquesta problemàtica en oferir una biografia molt més completa i més sòlidament documentada de la que fins ara es disposava.

En la primera part, que és, com he anunciat, la purament biogràfica i documental, Soler dóna compte de les fonts arxivístiques que ha explorat i de l'extensa bibliografia que han generat Joanot Martorell i el Tirant lo Blanc. Després de traçar una panoràmica general de la societat, la política i la vida cavalleresca del Regne de València durant la primera meitat del segle Xv, Soler ens presenta les principals fites biogràfiques de la família dels Vilaragut, des de la seua implicació en el plet successori dels anys I4IO-I4I3 al costat del comte d'Urgell fins que es retira definitivament a València, amb fama d'heroi però pobre de solemnitat, passant per la seua intervenció en les campanyes d'Itàlia, la seua dedicació temporal a la pirateria, la seua missió a Xipre, la seua participació en el setge de Rodes i el seu empresonament en la cort del «soldà de Babilònia» (I444), des d'on escapà. En tornar a València (I447), comencen els seus problemes amb els seus vassalls d'Albaida, fins que cau en desgràcia i perd el senyoriu (I456-I459). Vilaragut, de la mateixa manera que el seu amic Martorell, es veu obligat a manllevar diners de Martí-Joan de Galba per a poder menjar. Entre el I463 i el I464, mentre Joanot acabava de redactar el Tirant, Jaume de Vilaragut moria i el seu cos s'enterrà en el desaparegut monestir de Sant Francesc, en una tomba situada al costat de la que ocuparia, anys després, Isabel de Lloris, la impulsora de l'editio princeps del Tirant.

Acabada la prolixa exposició de dades, materials, anècdotes i documents, la segona part té un matís més assagístic, en el sentit d'una investigació historicoliterària. Soler aprofundeix després en la gènesi i en la datació del Tirant i en la debatuda qüestió dels seus destinataris i conclou que el text es dirigia solament als seus conciutadans. Igualment, l'historiador ens guia a recórrer els carrers i les cases de la ciutat de València i a conèixer les vides d'alguns personatges històrics coneguts i que es relacionen amb el Tirant - Galba, Isabel de Lloris_, juntament amb altres no tan coneguts fins ara - Carmesina, Eliseu, la viuda Centelles, etc. - que, pel que sembla, poden haver inspirat alguns dels subjectes narratius del text, d'acord amb el que, en general, delata l'homonímia. Finalment, l'autor tracta de relacionar la «tirania» exercida per 
Vilaragut sobre «Albaida, la blanca» com una raó de pes més per veure en l'excorsari una font d'inspiració per a Joanot Martorell.

L'assaig es tanca amb una reflexió sobre el sentit i la possible intenció del text de Martorell en relació amb aquests nous descobriments i que aprofita per a enllaçar amb el que la crítica moderna ha observat sobre la transformació interna del Tirant: des d'un pretès manual del perfecte cavaller fins a un decebedor $i$ "cínic» epitafi — mort de Tirant; triomf d'Hipòlit— de la cavalleria «clàssica». Però sobretot, insisteix Soler -i ho il.lustra mitjançant quadres sinòptics amb els quals ofereix una comparació entre els personatges reals i els subjectes narratius - a demostrar que la realitat social i urbana de la València del I45O-I460 influí, i molt, en el procés de concepció, disseny i redacció del Tirant.

L'apèndix documental, en el qual es reprodueix el testament de Jaume de Vilaragut (I45O) i on es mencionen la donzella Carmesina i altres personatges del seu entorn, és una eina de consulta molt útil. Com ho són també les il-lustracions i els arbres genealògics amb què el clouen, en què es fan paleses les relacions familiars i socials entre Jaume de Vilaragut, els Borja i els Martorell, entre altres.

Les novetats que Soler aporta són diverses. En primer lloc s'associa la conquesta del castell La Rocca d'Iscla, en la presa del qual (I423) participà Jaume de Vilaragut, amb una economia basada en l'extracció de la sal, amb la "conquesta de la Roca Salada» que dóna nom al protagonista del text de Martorell. Es relaciona, també, el nom de «Tirant» amb el caràcter superb i «tirànic» del personatge històric, de les (des)ventures del qual Soler ofereix copiosos detalls. Pel que fa a l'epítom «lo Blanc», l'historiador apunta una possible relació amb el feu de Jaume de Vilaragut, el senyoriu d'Albaida, "la Blanca». Potser és una interpretació agosarada, però no podem oblidar que els habitants de la major part del senyoriu eren moros arabòfons, que sabien perfectament que albaida vol dir 'blanc'. Soler també comenta el casament de Vilaragut amb una rica hereva, que en el cas d'haver engendrat descendència masculina, el fill d'ambdós, per qüestions testamentàries, hauria esdevingut el portador del llinatge i de les armes de «Martorell». De fet, Jaume de Vilaragut mantenia bones relacions tant d'amistat com econòmiques amb el cavaller Guillem Martorell, germà de Joanot. Aquests vincles podrien ajudar a explicar, sens dubte, la notable importància del món mariner en el text de Martorell així com el gran coneixement que d'aquest món manifesta l'escriptor valencià.

D’altra banda, l'amistat de Martorell amb un noble baró com Jaume de Vilaragut, àvid lector de relats artúrics i d'històries troianes, permet explicar, sempre segons la interpretació de Soler, l'ús de certes intertextualitats, com, verbigràcia, la peregrinació a Roma del I450 — curiosament, el mateix any de la peregrinació de 
Jaume de Vilaragut i del seu nebot—, a banda de la referència explícita als noms reals d'alguns cardenals. Tot plegat ajudà Martí de Riquer a localitzar l'acció del Tirant en un moment contemporani a l'autor. S'hi menciona, a més, una carta que el rei de Xipre adreçà al soldà de Babilònia, reproduïda en el Tirant, la presència del qual en el text podria explicar-se per l'estada de Jaume de Vilaragut, en qualitat de mercenari, al servei del rei de Xipre.

Igualment, Soler recorda que Vilaragut i Martorell convisqueren a Nàpols en la dècada del I450, cosa que pogué haver afavorit la transferència d'informació entre els dos amics — anècdota que, per cert, ja havia estat notada i novel-lada anteriorment per Eduard Mira en els seus Escacs de mort (Alzira, Bromera, 2009). A continuació, i prenent el testimoni de Jerónimo Zurita, Soler comenta el fet que el papa valencià Calixt III, just després de ser coronat a Roma (I455), encarregà a Jaume de Vilaragut la capitania de deu galeres armades que havien d'obrir la croada de recuperació de Constantinoble. És de sobres conegut que Alfons el Magnànim posà entrebancs tant $\mathrm{a}$ aquest com a d'altres projectes de croada encapçalats pel papa Borja; d'aquesta manera, la redempció de Bizanci només podria ser executada sobre el paper, en l'escriptori de Joanot Martorell.

Potser una de les qüestions més interessants que Soler explora radica en la identificació de personatges de carn i ossos que habitaven l'entorn social i urbà de Martorell durant els anys I447-I462 i que perfectament podrien haver aprofitat d'inspiració als subjectes narratius. A alguns els delata la simple homonímia: és el cas de la donzella Eliseu Martínez de Vera — cosina de Isabel, l'enamorada del poeta Joan Roís de Corella-, el comportament de la qual podria concordar amb el de la donzella Eliseu del Tirant. Un altre exemple és el de Ponç de Montpalau, emparentat amb el mateix Martorell i fidel servidor de Jaume de Vilaragut, a qui acompanyà en el periple mediterrani; aquest presenta meridianes concomitàncies amb Diafebus de Muntalt. Per això, un altre dels subjectes narratius del text de Martorell, la viuda Reposada, es relaciona, segons Soler, amb la jove sogra del corsari, la viuda Centelles: matrona carismàtica, a qui li agradava fer-se acompanyar de dos escuders per València — com el subjecte narratiu del Tirant_, que estimava en demesia el cavaller i que posà en venda una esclava russa anomenada Margarida (¿la Maragdina del Tirant?). No falta en la casa de Vilaragut un extens i frondós hort, alhora que un esclau de color i ancià que podria encaixar amb Lauseta, un altre dels personatges que poblen l'univers narratiu de Martorell. A banda d'aquests parentescos sobradament plausibles, també es posen de relleu les relacions familiars i de veïnatge, entre altres, que existien entre Jaume de Vilaragut i altres personatges de la València «del segle d'or», com per exemple Isabel 
de Lloris —impulsora de l'edició del Tirant el I490-, Jaume Roig, Joan Roís de Corella o la poderosíssima família Borja.

Una de les aportacions més interessants de Soler és la documentació històrica d'una donzella de nom Carmesina, "criada» personal de Vilaragut, i molt beneficiada per ell. Soler la identifica com una possible alliberada d'origen oriental que amb el temps es convertí en l'amant del cavaller. A més d'aquesta Carmesina — nom poc corrent en l'onomàstica habitual de l'època-, l'historiador valencià identifica altres dues Carmesines nascudes en vespres del Tirant: una és filla de Galceran de Requesens, batlle general i governador general de Catalunya, i amic personal d'Alfons el Magnànim, i l'altra era filla del governador del Regne de València, Joan Roís de Corella. Casualment, Requesens era cunyat de Jaume i fervent protector seu, de manera que la tria del nom de pila de Carmesina podria ser producte d'un apadrinament. De la mateixa manera, els Corella gaudien d'una amistat molt diàfana amb Jaume i el baptisme de la Carmesina de Corella coincideix amb la venda que Vilaragut féu al comte de Cocentaina d'una de les seues baronies en I452. Siga com siga, el cert és que les tres Carmesines reals es relacionen amb el personatge en qüestió, Vilaragut, cosa que mena Soler a concloure que la quarta Carmesina - la princesa producte de la imaginació de Martorell— també cal posar-la en relació amb la Carmesina de Vilaragut.

No hi ha dubte que aquesta mena de «biografia crítica» de Soler il.lumina alguns, i no pocs, elements socioculturals presents en el Tirant, per la qual cosa els que ens dediquem a la història cultural i literària hem de congratular-nos per la seva publicació. Tanmateix, al llarg de la lectura, i més especialment en l'última part, he trobat a faltar una major precisió en l'ús de determinats termes i conceptes que s'han superat ja des de fa alguns anys, alguns dels quals l'autor empra potser amb massa freqüència, sense criticar-los. En citaré només un parell: «subjecte narratiu» hauria d'aparèixer en comptes de "personatge»; «text», en comptes de «obra». A vegades també recorre a expressions massa col-loquials. Però allò que més m'ha sorprès és l'ús de «novel.la» per a referir-se al Tirant. És cert que Martí de Riquer diferencià entre el «libro de caballerías», en el qual les aventures entrelligades d'un heroi gairebé sobrehumà se situen en un lloc exòtic i en un passat remot, i la "novel.la cavalleresca», en la qual es narren les aventures d'un heroi més humà, i que Soler se'n fa ressò. Ara bé, no comparteixo aquesta distinció pel simple fet que l'ús del terme «novel-la» implica «nou», ja que «novel» deriva de la forma italiana «novella» — una nova història— i, en conseqüència, la paraula forma part de la semàntica de la modernitat. I, en aquest sentit, Tirant pot ser qualificat de tot, llevat de «modern», sensu lato. En això, tothom hi estaria d'acord. A més, si fem cas al que s'ha dit més amunt, que el Tirant pot ser llegit com un manual del perfecte cavaller i, per tant, de caràcter didàctic, a aquesta novel.la li encaixaria molt millor el 
rètol de «llibre», gènere literari vinculat al didactisme. Dit això, i assumint el perill de repetir-me, les meues «crítiques» no desmereixen ¡en absolut! l'excel-lent investigació i la fresca redacció d'aquest llibre, que hauria de passar a formar part de les nostres biblioteques des d'ara mateix.

EnRic Mallorquí-Ruscalleda California State University-Fullerton emallorq@fullerton.edu 